\title{
Temporary turnout for free exercise in groups: effects on the behaviour of competition horses housed in single stalls
}

Hanna Werhahn*, M. Sc.; Engel F. Hessel, PD Dr.; Hanna Schulze, M. Sc.; Herman F. A. Van den Weghe, Prof. Dr. Ir.

Department of Animal Sciences, Division: Process Engineering, Georg-AugustUniversity of Goettingen, Universitaetsstr. 7, D-49377 Vechta, Germany

Published in

Journal of Equine Veterinary Science 31 (2011) 417-425

* Corresponding author. Universitaetsstr. 7, D-49377 Vechta, Germany. Tel.: 0049-551-3922176. Fax: 0049-4441-15448. E-mail address: hwerhah@gwdg.de (H. Werhahn).

Abbreviations: $\mathrm{NT}=$ no turnout; $\mathrm{TBT}=$ turnout before training; $\mathrm{TAT}=$ turnout after training. 


\section{ABSTRACT}

In Germany most competition horses are housed in single stalls and free exercise is not permitted in many cases. The reason for not allowing free exercise is mostly the risk of injury. Additionally, opinions exist that the horses' demand for exercise is fulfilled by training or that the horses' willingness to perform is negatively influenced by free exercise. In the present study, three turnout practices were investigated with regard to their effect on the behaviour of four horses: daily training without free exercise (NT), two-hour turnout (for free exercise) before training (TBT) and two-hour turnout after training (TAT). The aim of the study was to determine any differences in the horses' behaviour between the three treatments. The horses' behaviour in the stable was observed via video recordings, the behaviour during turnout was observed directly and the behaviour during training was evaluated by the riders with the aid of a questionnaire. Additionally, the distance covered during turnout was measured by GPS devices. The behaviour within the stall was more restless in the treatment NT - which became apparent in significantly more frequent changes between behaviours compared to the treatments with turnout. The results of GPS measurement during turnout showed a significantly shorter distance covered when horses were ridden before they were turned out (TAT) compared to TBT. If the horses were turned out after training (TAT), they also showed less trotting and cantering and more standing/dozing. The horses' willingness to perform was not significantly different between the three treatments.

Keywords: horse, turnout, behaviour, single stall 


\section{Introduction}

In Germany most competition horses are housed in single stalls, in many cases without any opportunity for free exercise outside the stall[1]. This way of life constricts the natural behaviour patterns of the horse to a great extent. In the wild, horses spend up to 16 hours a day foraging for food, which generally happens in a slow and steady walk [2,3]. Trotting is performed in exploration behaviour and display behaviour in reproduction. Cantering is demonstrated only for short times in flight or playing behaviour [4]. This is why the German guidelines for the evaluation of equine housing systems regarding aspects of animal protection explicitly state that horses housed in single stalls need exercise according to their physiological requirements for several hours a day [5]. These guidelines also point out that controlled exercise is not able to replace free exercise. In practice, the limitation of free exercise, especially in competition horses, is wide spread and mostly justified by the concomitant risk of injury. Furthermore, there are assumptions that the demand of exercise in the horse is satisfied by training or that free exercise reduces the horse's willingness to perform. As a consequence of a life predominantly spent in stables, many horses suffer from diseases of the musculoskeletal system $[6,7,8]$ and respiratory system $[9,10]$ as well as abnormal behaviour $[11,12,13]$.

As behaviour is a consequence of motivational states, behaviour quantification indicates the intension of motivation in the animal. Therefore, to the experienced observer the behaviour of an animal provides information on the state of its well-being and so on the animal welfare qualities of a particular housing system [14]. Earlier investigations have revealed that locomotion activity during turnout is reduced if horses are trained in a circular horse walker before turnout compared to no training at all [15]. It was concluded that training is able to partly fulfil a horse's exercise requirements. Furthermore, it was found that horses behave much quieter during turnout if it happens daily compared to turnout once a week [16]. Caanitz et al. [17] observed more time spent lying down at night in a group of horses that was trained on a treadmill five times a week compared to a group that was not trained.

The aim of the present study was a systematic investigation of the influences of three turnout practices on the behaviour of a group of competition horses housed in single stalls. As they are widely used in Germany, the turnout practices "two-hour turnout before training" (TBT), "two-hour turnout after training" (TAT) and "training without turnout" (NT) were selected. The behaviour patterns of the horses in the stable, during turnout and during training were considered so that it could be revealed which of the investigated treatments combines both the horses' and the riders' requirements in the best way possible. 


\section{Material and methods}

\subsection{Location of the study}

The research was undertaken in a stable in Settmarshausen (county of Goettingen, Lower Saxony, Germany) in the period from $11^{\text {th }}$ May until $19^{\text {th }}$ June, 2008. The stable contained 24 single stalls $(3.00 \times 3.80 \mathrm{~m})$ in two rows with an aisle (width: $3.00 \mathrm{~m})$ in the middle (Fig. 1). The stalls were separated by $1.20 \mathrm{~m}$ hardwood walls with $2.05 \mathrm{~m}$ vertical lattice bars (distance between bars: $5.80 \mathrm{~cm}$ ) on top. The fronts had sliding doors (width: $1.50 \mathrm{~m}$ ) consisting of the same material. The brick walls of the stable building formed the back of the stalls. The horses had no possibility to put their heads outside or into the aisle. The stable ceiling height was $3.26 \mathrm{~m}$. Along the long sides of the stable, 28 windows $(1.00 \times 1.00 \mathrm{~m})$ in a row formed light bands underneath the ceiling. The windows were left open slightly for ventilation. Two doors $(3.00 \times 3.00 \mathrm{~m})$ at the ends of the aisle were open day and night. Each stall was equipped with a feeding trough for concentrates, an automatic drinking trough and a salt block. Four stalls situated next to each other were used for the investigation (Fig. 1).

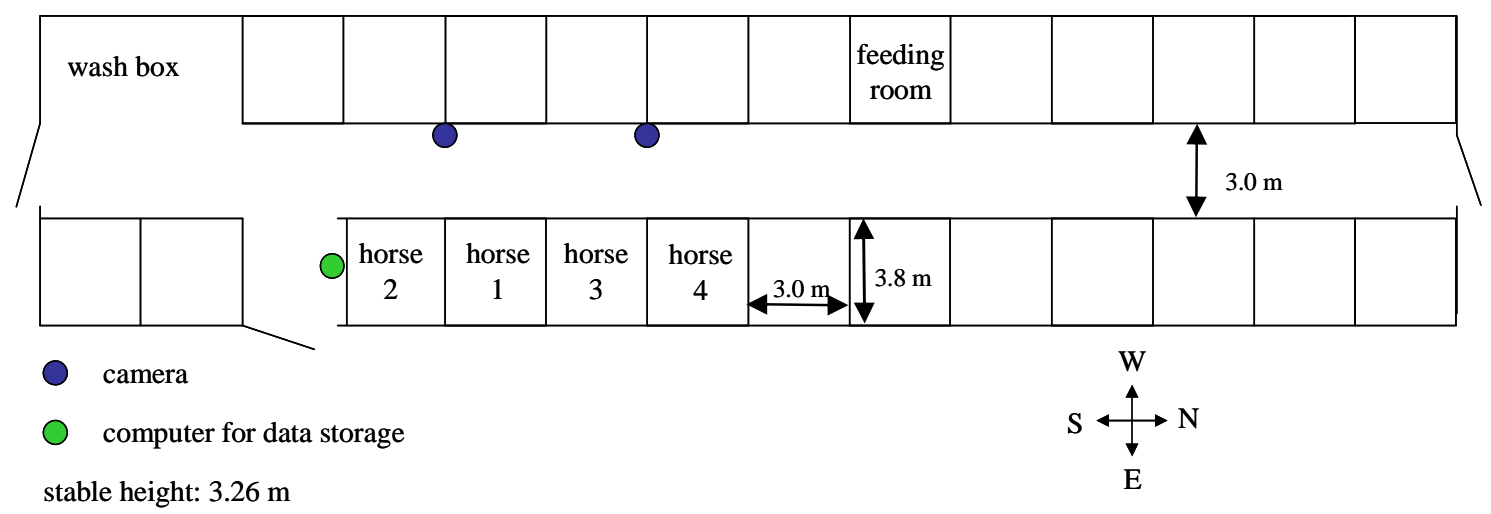

Fig. 1. Outline of the stable including the positions of the experimental stalls (Horses 1$4)$, cameras and computer.

Next to the stable, to the east, was a $35 \times 50 \mathrm{~m}$ sand area used for riding and turnout. The area was bordered by a wooden fence (height: $1.5 \mathrm{~m}$ ), with an electrical band on top. For the study, a turnout area of 10 x $35 \mathrm{~m}$ was separated by an electrical fence. This size was selected to give the horses enough space for free exercise (walk, trot and canter were possible; the German guidelines advise at least $150 \mathrm{~m}^{2}$ for two horses [5]) and to allow training of the horses in the remaining area.

During the investigation, the air temperature varied between 9 and $23^{\circ} \mathrm{C}$ and the relative humidity varied between 51 and $99 \%$. 


\subsection{Animals}

Four German Warmblood Horses (height between 1.63 and $1.70 \mathrm{~m}$; weight between 600 and $650 \mathrm{~kg}$ ) were used for the investigation. All four horses were schooled in dressage and show jumping and - except for Horse 3 - were deployed in competitions in one of these disciplines. Horse 1 (H1) was a nine-year-old Hanoverian mare, who had competed in dressage up to intermediate class and was schooled in show jumping at novice level. Horse 2 (H2) was an eight-year-old Hanoverian mare, who had competed in show jumping up to advanced class and was schooled in dressage at intermediate level. Horse 3 (H3) was a five-year-old Hanoverian gelding, schooled in dressage and show jumping at pre-novice level. Horse 4 (H4) was an eleven-year-old gelding from Saxony-Anhalt, who had competed in show jumping up to advanced class and was schooled in dressage at an intermediate level. All four horses were housed in the experimental stable and turned out 3-4 times a week (for 1-2 hours in groups of 2-4 horses) for at least three months before the investigation was started. For the investigation, $\mathrm{H} 1$ and $\mathrm{H} 2$ remained in their own stalls. They were also used to joint turnout. $\mathrm{H} 3$ and $\mathrm{H} 4$ were moved into their experimental stalls and acclimatized to joint turnout two weeks before the investigation started. The riders were asked to retain their way of training during the investigation according to their normal routine.

\subsection{Bedding materials and feed}

All experimental stalls were strewn with wheat straw. New straw (ca. $10 \mathrm{~kg}$ per stall) was given every morning after feeding. The stalls were mucked out once every four weeks.

Concentrates (oats and barley, 3:1 mix) were fed three times a day (06:30 am, 12:00 am, 05:00 pm). At 12:00 am, soaked sugar beet pulp was given additionally and at 05:00 pm mineral feed was added to the concentrates. Hay was given once a day at 04:30 pm. The particular amounts of feed were specific for each horse (according to requirement and performance; Table 1) and remained constant over the course of the experiments. Feeding quality and type also remained constant. Water was available at all times for each individual horse. 
Table 1: Amounts of feed used during the investigation.

\begin{tabular}{|c|c|c|c|}
\hline & 6:30 AM & 12:00 AM & 4:30/5:00 PM \\
\hline horse 1 & $2 \mathrm{~kg}$ oats and barley (3:1 mix) & $\begin{array}{l}2 \mathrm{~kg} \text { oats and barley ( } 3: 1 \mathrm{mix}) \\
2 \mathrm{~kg} \text { soaked sugar beet pulp }\end{array}$ & $\begin{array}{l}4 \mathrm{~kg} \text { hay } \\
2 \mathrm{~kg} \text { oats and barley ( } 3: 1 \mathrm{mix}) \\
50 \mathrm{~g} \text { mineral feed }\end{array}$ \\
\hline horse 2 & $2 \mathrm{~kg}$ oats and barley (3:1 mix) & $\begin{array}{l}2 \mathrm{~kg} \text { oats and barley }(3: 1 \mathrm{mix}) \\
2 \mathrm{~kg} \text { soaked sugar beet pulp }\end{array}$ & $\begin{array}{l}7 \mathrm{~kg} \text { hay } \\
2 \mathrm{~kg} \text { oats and barley }(3: 1 \mathrm{mix}) \\
50 \mathrm{~g} \text { mineral feed }\end{array}$ \\
\hline horse 3 & $1.5 \mathrm{~kg}$ oats and barley (3:1 mix) & $\begin{array}{l}1.5 \mathrm{~kg} \text { oats and barley }(3: 1 \mathrm{mix}) \\
2 \mathrm{~kg} \text { soaked sugar beet pulp }\end{array}$ & $\begin{array}{l}6 \mathrm{~kg} \text { hay } \\
1.5 \mathrm{~kg} \text { oats and barley }(3: 1 \mathrm{mix}) \\
50 \mathrm{~g} \text { mineral feed }\end{array}$ \\
\hline horse 4 & $2.5 \mathrm{~kg}$ oats and barley (3:1 mix) & $\begin{array}{l}2.5 \mathrm{~kg} \text { oats and barley }(3: 1 \mathrm{mix}) \\
2 \mathrm{~kg} \text { soaked sugar beet pulp }\end{array}$ & $\begin{array}{l}4 \mathrm{~kg} \text { hay } \\
2.5 \mathrm{~kg} \text { oats and barley ( } 3: 1 \mathrm{mix}) \\
50 \mathrm{~g} \text { mineral feed }\end{array}$ \\
\hline
\end{tabular}

\subsection{Measurement techniques}

Two video cameras (Panasonic CCTV WV-BP 310, Panasonic Corporation, Kadoma, Osaka, Japan) were fixed underneath the ceiling opposite to the experimental stalls (Fig. 1), so each camera recorded the behaviour of two horses. To allow recording at night, infrared light sources were fixed underneath the ceiling inside each stall. The videos were recorded in digital format using MV4R Digital Time Lapse board (MSH Video, Riga, Latvia). A computer to record data (HP Compaq dx2200 Microtower, Hewlett-Packard Company, Palo Alto, California, USA) and a monitor screen to control recordings were located in a metal box within the stable. The recordings were stored daily on external hard disks. Subsequently, all the data were analyzed using the Observer XT 8.0 (Noldus Information Technology, Wageningen, The Netherlands).

Two GPS (global positioning system) devices - Garmin Forerunner 205 (Garmin, Olathe, Kansas, USA) - were used to record the distance covered by the horses during turnout. The devices were fixed on the horses' head collars. Afterwards, the measurement data was read out and stored using the software program Garmin Training Center (Garmin, Olathe, Kansas, USA). The behaviour of the horses in the turnout area was documented by direct observation using a scan sampling method (observation interval: 5 minutes).

The riders registered the horses' behaviour during training with the aid of a questionnaire. Amongst others, the horses' behaviour during the working phase (answer possibilities: particularly quiet, rather quiet, normal, rather agitated, particularly agitated), its concentration (answer possibilities: particularly good, rather good, normal, rather bad, particularly bad) and contumacy (answer possibilities: particularly little, rather little, normal, rather intense, particularly intense) had to be described.

During the experiments, two Tinytag Plus 2 (Gemini Data Loggers Ltd., Chichester, UK) recorded temperature and relative humidity hourly both within and outside the stable. 


\subsection{Experimental design}

The whole investigation took six weeks and was divided in three two-week-periods. The experimental horses were divided in two groups (Group $1=\mathrm{H} 1$ and H2; Group $2=$ H3 and H4). During the investigation all horses passed through three treatments each lasting for two weeks. In the first treatment the horses were trained daily (between 8.00 and $12.00 \mathrm{am}$ ) and free exercise was not allowed (NT). In the second treatment the horses were turned out from 8.00 to 10.00 am and trained between 10.00 and $12.00 \mathrm{am}$ (TBT). In the third treatment the horses were trained between 8.00 and 10.00 am and turned out from 10.00 to 12.00 am (TAT). The test procedure is presented in Table 2. In the first period of the experiments (weeks 1 and 2) both groups passed the treatment NT. In the second period (weeks 3 and 4) Group 1 passed TBT and Group 2 passed TAT. In the third period (weeks 5 and 6) Group 1 passed TAT and Group 2 passed TBT. Depending on the particular training time, between training and turnout respectively turnout and training - the horses spent 10 to 60 minutes within their stall. Training was carried out by two experienced riders (one training the mares, one training the geldings) who also rode the horses in competitions. The horses' behaviour during turnout and training was collected every other day for each group (one day Group 1, next day Group 2). Because the horses needed to get used to the new rhythm (turnout and training times), the first three days of each period were not analysed.

Table 2: Test procedure.

\begin{tabular}{lcc}
\hline & $\begin{array}{c}\text { Group 1 } \\
(\text { Horse 1+2) }\end{array}$ & $\begin{array}{c}\text { Group 2 } \\
(\text { Horse 3+4) }\end{array}$ \\
\hline period 1 (week 1+2) & NT & NT \\
period 2 (week 3+4) & TAT & TBT \\
period 3 (week 5+6) & TBT & TAT \\
\hline NT = no turnout; TAT = turnout after training; TBT = \\
turnout before training
\end{tabular}

\subsection{Data collection}

Video recordings of the horses' behaviour in the stalls were analysed on three days of each period of the investigation. Because the horses were supposed to acclimatize to the treatment (rhythm of the day), the days at the end of the second week were chosen for behaviour observation. Continuous observations were carried out by one person between $12.30 \mathrm{pm}$ and 7.30 am the next morning (19 h), while all horses were in their stalls. Frequency, mean duration per appearance and total duration within the 19 hours were documented for each type of behaviour. The observed behaviours were grouped into nine categories: "eating" (including eating hay and concentrates), "standing alert" (including watching the surroundings attentively or nervously), "occupation with equipment" (investigating stall equipment like trough, salt block, etc.), "occupation with bedding" (investigating or eating bedding material), "dozing" (stand quietly, one 
hind leg relaxed), "sternal recumbency" and "lateral recumbency". Additionally, the frequencies of aggressive behaviour (kicking, ears back or biting directed at their neighbours) and locomotion (more than three steps without interruption) were recorded.

Direct observations were also carried out by one person and produced 22 behaviour protocols in Period 2 and 22 in Period 3. The behaviours "standing/dozing", "standing/watching", "standing/occupation", "walking", "trotting/cantering" and social "interaction" were recorded in the protocols. The observed horses also carried GPS devices measuring the distance covered and speed.

To create more concrete statements about the horses' willingness to perform out of the differentiated answers revealed by the questionnaire, the riders' answers about behaviour during the working phase, including the horses' concentration and contumacy were summarized into the feature "willingness to perform". In addition to the questionnaire, the total duration of training was documented.

\subsection{Statistical analysis}

The statistical evaluation of the data was carried out with the software program SAS 9.1 (SAS Inst. Inc., Cary NC, USA). For all of the data, the analysis of variance of normally distributed data was computed using the GLM procedure. For data that could not be transformed into Gaussian distribution, influences of fixed effects and interactions were estimated using the NPAR1WAY procedure and WILCOXON TWOSAMPLE TEST to test the significance of the effects. The significance level was $P \leq$ 0.05 and $P$-values between 0.05 and 0.1 were seen as tendencies $(t$-test).

In total, the video observations created 36 data sets (three days in three treatments for four horses). The behaviour data was transformed into Gaussian distribution if possible by the procedures showed in Table 3. For each of the behaviours, the fixed effects of horse and treatment (no turnout, turnout before training, turnout after training) and the interaction between "horse and treatment" were considered.

Table 3: Data transformation of the behaviour patterns in the stable to create Gaussian distributions.

\begin{tabular}{|c|c|c|c|}
\hline transformation & total duration & mean duration & frequency \\
\hline $\begin{array}{l}\text { no transformation } \\
\text { necessary }\end{array}$ & $\begin{array}{l}\text { occupation with } \\
\text { bedding, dozing, } \\
\text { sternal recumbency }\end{array}$ & dozing & standing alert \\
\hline logarithm & standing alert & $\begin{array}{l}\text { standing alert, } \\
\text { occupation with } \\
\text { bedding, eating }\end{array}$ & $\begin{array}{l}\text { occupation with } \\
\text { bedding, dozing, } \\
\text { eating, locomotion, } \\
\text { sternal recumbency }\end{array}$ \\
\hline square root & eating & & $\begin{array}{c}\text { occupation with } \\
\text { equipment }\end{array}$ \\
\hline $\begin{array}{l}\text { no transformation } \\
\text { possible }\end{array}$ & $\begin{array}{l}\text { occupation with } \\
\text { equipment, lateral } \\
\text { recumbency }\end{array}$ & $\begin{array}{l}\text { occupation with } \\
\text { equipment, sternal } \\
\text { recumbency, lateral } \\
\text { recumbency }\end{array}$ & $\begin{array}{l}\text { aggression, lateral } \\
\text { recumbency }\end{array}$ \\
\hline
\end{tabular}


The direct observation of the horses during turnout generated 32 behaviour protocols. In the analysis, as the observation interval was 5 minutes, each recorded behaviour was considered to have lasted for $4.17 \%$ of the total turnout time (i.e. for 5 minutes out of a total turnout of 120 minutes).

Two sets of behaviour data had to be transformed into Gaussian distribution by taking the logarithm for the behaviour "stand/dozing" and by taking the square root for the behaviour "walk". The behaviours "social interaction" and "trot/canter" could not be transformed into Gaussian distribution. The fixed effects horse and treatment (turnout before training, turnout after training), turnout hour and the interaction between "horse and treatment", "horse and hour" and "hour and treatment" were considered for all the behaviours.

Measurements of the distance covered $(\mathrm{km})$ and average speed $(\mathrm{km} / \mathrm{h})$ during turnout were available for 28 days. The data was available in Gaussian distribution. The fixed effects of horse and treatment, the interaction between "horse and treatment" and the co variable of the temperature were considered. Additionally, the coefficient of correlation (Pearson product-moment correlation coefficient, r) between distance and speed was computed.

Questioning the riders about the horses' willingness to perform produced 46 analysable questionnaires. The data of the duration of training was available in normal distribution and the fixed effects of horse and treatment and the interaction between "horse and treatment" were considered. Additionally, the coefficient of correlation (Pearson product-moment correlation coefficient, r) between the duration of training and the behaviour of the horse in the working phase of training was computed.

\section{Results}

\subsection{Behaviour in the stall}

For the daily observation time of 19 hours, no significant differences could be found in total duration of the behaviours "standing alert", "occupation with bedding", "dozing", "sternal recumbency", "lateral recumbency" and "eating". Only "occupation with equipment" was performed significantly longer in the treatment NT compared to the treatments with turnout (TAT $P=0.0382$; TBT $P=0.0435$ ). The mean duration per appearance revealed significant differences in the behaviours "standing alert" and "dozing". In the treatment TAT, the mean duration of "standing alert" was significantly longer compared to the other treatments (NT $P=0.0054$; TBT $P=0.0272$ ). "Dozing" also showed the longest mean duration in the treatment TAT, which was significantly longer than "dozing" in the treatment NT $(P=0.0031)$. The treatments NT and TBT were not significantly different (Table 4). Figure 2 shows the mean frequency of appearance of the behaviours "standing alert", "aggression", "occupation with equipment", "occupation with bedding", "dozing", "sternal recumbency" and "lateral 
recumbency". All of the behaviours - except "occupation with bedding" - were performed most frequently in the treatment NT. The difference was significant compared to the treatment TAT in the behaviours "aggression", "occupation with equipment", "dozing" and "sternal recumbency" $(P \leq 0.05)$. "Occupation with equipment" was also performed significantly more frequently in the treatment NT compared to the treatment TAT $(P=0.0071)$, while "dozing" showed a tendency in this direction $(P=0.0856)$. Tendencies showing the described direction also existed in "aggression" and "occupation with equipment" $(0.1<P>0.05)$. "Occupation with bedding" showed the least frequency in the treatment NT. The difference was significant compared to both treatments with turnout $(P \leq 0.05)$. The behaviour "locomotion" did not show any differences in frequency between the treatments.

Table 4: Total duration (hours) and mean duration per appearance (minutes) of the behaviours "standing alert", "occupation with equipment", "occupation with bedding", "dozing", "sternal recumbency", "lateral recumbency" and "eating" in the stable, subdivided according to treatment.

\begin{tabular}{|c|c|c|c|c|c|c|}
\hline \multirow[b]{2}{*}{ behaviour } & \multirow[b]{2}{*}{ treatment } & \multirow[b]{2}{*}{ n } & \multicolumn{2}{|c|}{$\begin{array}{c}\text { total duration } \\
\text { (hours) }\end{array}$} & \multicolumn{2}{|c|}{$\begin{array}{c}\text { mean duration } \\
\quad \text { (minutes) }\end{array}$} \\
\hline & & & LSM/M & $\mathrm{SE} / S D$ & $\mathbf{L S M} / M$ & $\mathrm{SE} / S D$ \\
\hline \multirow{3}{*}{$\begin{array}{l}\text { standing } \\
\text { alert }\end{array}$} & NT & 12 & $2.16^{\mathrm{a}}$ & 0,33 & $6.38^{\mathrm{a}}$ & 0,87 \\
\hline & TAT & 12 & $2.70^{\mathrm{a}}$ & 0,33 & $9.96^{\mathrm{b}}$ & 0,87 \\
\hline & TBT & 12 & $1.92^{\mathrm{a}}$ & 0,33 & $7.22^{\mathrm{a}}$ & 0,87 \\
\hline \multirow{3}{*}{$\begin{array}{l}\text { occupation } \\
\text { with } \\
\text { equipment }\end{array}$} & NT & 12 & $1.74^{a}$ & 1,15 & $7.03^{a}$ & 4,66 \\
\hline & TAT & 12 & $0.55^{b}$ & 1,08 & $4.72^{a}$ & 6,66 \\
\hline & TBT & 12 & $0.62^{b}$ & 0,63 & $5.48^{a}$ & 5,03 \\
\hline \multirow{3}{*}{$\begin{array}{l}\text { occupation } \\
\text { with bedding }\end{array}$} & NT & 12 & $4.81^{\mathrm{a}}$ & 0,41 & $16.82^{\mathrm{a}}$ & 1,97 \\
\hline & TAT & 12 & $6.06^{\mathrm{a}}$ & 0,41 & $20.37^{\mathrm{a}}$ & 1,97 \\
\hline & TBT & 12 & $6.67^{\mathrm{a}}$ & 0,41 & $20.37^{\mathrm{a}}$ & 1,97 \\
\hline \multirow[t]{3}{*}{ dozing } & NT & 12 & $4.13^{\mathrm{a}}$ & 0,31 & $16.73^{\mathrm{a}}$ & 1,93 \\
\hline & TAT & 12 & $4.19^{\mathrm{a}}$ & 0,31 & $25.70^{\mathrm{b}}$ & 1,93 \\
\hline & TBT & 12 & $4.90^{\mathrm{a}}$ & 0,31 & $20.38^{\mathrm{ab}}$ & 1,93 \\
\hline \multirow{3}{*}{$\begin{array}{l}\text { sternal } \\
\text { recumbency }\end{array}$} & NT & 12 & $3.01^{\mathrm{a}}$ & 0,20 & $22.35^{a}$ & 11,44 \\
\hline & TAT & 12 & $2.51^{\mathrm{a}}$ & 0,20 & $21.62^{a}$ & 13,32 \\
\hline & TBT & 12 & $2.58^{\mathrm{a}}$ & 0,20 & $23.64^{a}$ & 14,36 \\
\hline \multirow{3}{*}{$\begin{array}{l}\text { lateral } \\
\text { recumbency }\end{array}$} & NT & 12 & $0.24^{a}$ & 0,24 & $2.40^{a}$ & 2,04 \\
\hline & TAT & 12 & $0.23^{a}$ & 0,29 & $2.11^{a}$ & 2,22 \\
\hline & TBT & 12 & $0.21^{a}$ & 0,15 & $2.66^{a}$ & 2,39 \\
\hline \multirow[t]{3}{*}{ eating } & NT & 12 & $3.04^{\mathrm{a}}$ & 0,40 & $25.29^{\mathrm{a}}$ & 5,90 \\
\hline & TAT & 12 & $2.40^{\mathrm{a}}$ & 0,40 & $35.94^{\mathrm{a}}$ & 5,90 \\
\hline & TBT & 12 & $2.36^{\mathrm{a}}$ & 0,40 & $32.57^{\mathrm{a}}$ & 5,90 \\
\hline
\end{tabular}

$\mathrm{n}=$ number of values. LSM = least squares means. $\mathrm{SE}=$ standard error. $\mathrm{M}=$ means. $\mathrm{SD}=$ standard deviation. $\mathrm{NT}=$ no turnout; $\mathrm{TAT}=$ turnout after training; TBT $=$ turnout before training. $\mathrm{a}, \mathrm{b}=$ least squares means/ means within a behaviour with different letters are significantly different $(\mathrm{P}<0.05)$. 


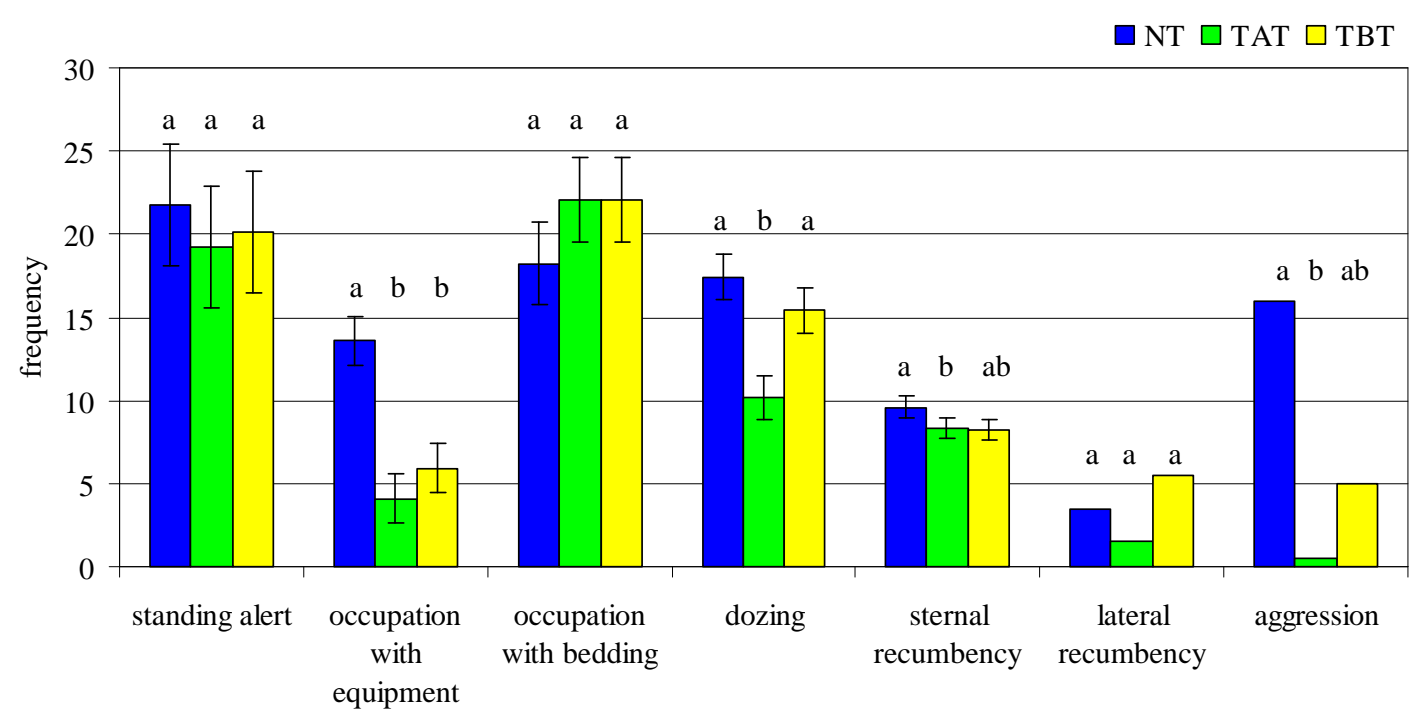

Fig. 2. Least squares means and standard errors of the frequency of standing alert, occupation with equipment, occupation with bedding, dozing and sternal recumbency; median of the frequency of lateral recumbency and aggression, subdivided according to treatment [observation period $19 \mathrm{~h} ; \mathrm{n}=36$; NT $=$ not turnout; TAT $=$ turnout after training; TBT = turnout before training; $\mathrm{a}, \mathrm{b}=$ least squares means/median within $\mathrm{a}$ behaviour with different letters are significantly different $(P<0.05)]$.

\subsection{Behaviour during turnout}

The behaviour of the horses during the two-hour turnout is presented in Fig. 3. In the treatment TBT, the horses showed significantly more active behaviour during turnout, such as "walking" $(P=0.0278)$ and "standing/watching" $(P=0.0122)$. If training happened before turnout (TAT), "walking" was reduced by $30.58 \%$ and "trotting/cantering" was reduced by $66.67 \%$. Resting behaviour like "standing/dozing" was performed significantly longer in the treatment TAT $(P=0.0013$; extended by $58.88 \%$ ). Social interaction was performed for about 13 minutes (16\% of turnout time) as well before as after training. All behaviours were performed in both turnout hours, while "standing/occupation", "walking", "trotting/cantering" and "interaction" were performed slightly longer in the first hour and "standing/watching" and "standing/dozing" slightly longer in the second hour. The only significant differences between the first and second hour were found in TAT in the behaviours "standing/dozing" (significantly longer in the second hour; $P=0.0194$ ) and "standing/occupation" (significantly shorter in the second hour; $P<0.0001$ ). 


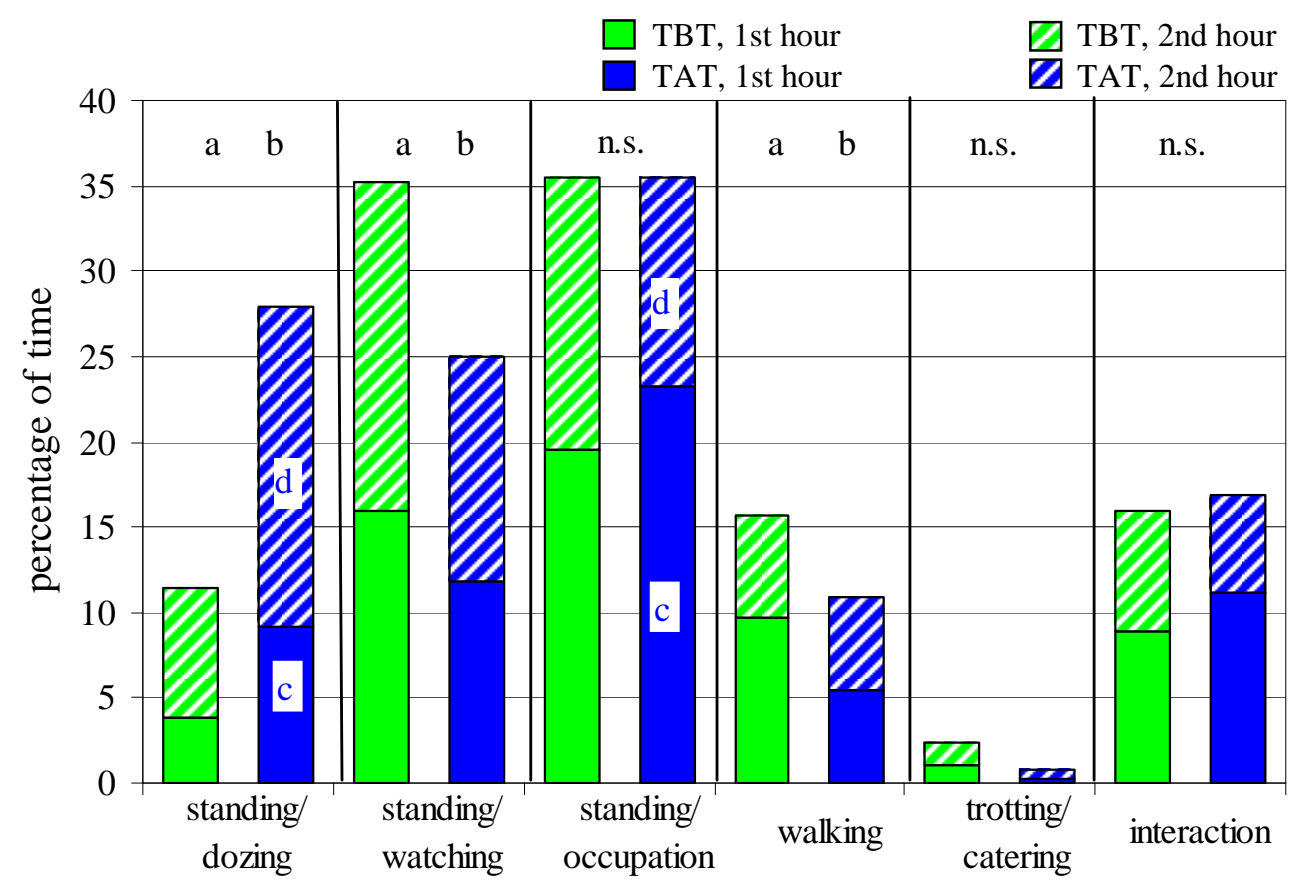

Fig. 3. Least squares means of percentage for the behaviours "standing/dozing", "standing/watching", "standing/occupation", "walking" and means for the behaviours "trotting/cantering" and "interaction" during turnout subdivided according to turnout hour and treatment. [ $\mathrm{n}=32$ (16 measurements in each treatment); NT = not turnout; $\mathrm{TAT}=$ turnout after training; TBT $=$ turnout before training; n.s. = not significant; $\mathrm{a}, \mathrm{b}=$ least squares means/means within a behaviour with different letters are significantly different; c, d $=$ least squares means/means within the bar $\left(1^{\text {st }}\right.$ and $2^{\text {nd }}$ hour $)$ with different letters are significantly different $(P<0.05)]$.

\subsection{Distance covered during turnout}

The distance covered by the horses during turnout was significantly shorter when they had been trained before turnout (TAT) compared to TBT ( $P=0.0003$; Fig. 4$)$. But the individual horses did not show the same reaction regarding the particular turnout time. $\mathrm{H} 1$ and $\mathrm{H} 2$ covered a significantly shorter distance in TAT $(P=0.0090$ and $P=0.0002$, respectively). The distances of $\mathrm{H} 3$ and $\mathrm{H} 4$ were not significantly different $(P=0.1114$ and $P=0.3379$, respectively), but $\mathrm{H} 4$ covered a longer distance when it was turned out after training (TAT). The distance covered during training did not significantly influence the distance covered during turnout $(P=0.4416)$. The distance covered was significantly correlated to the speed the horses moved at during turnout $(\mathrm{r}=1 ; P<$ 0.0001). 


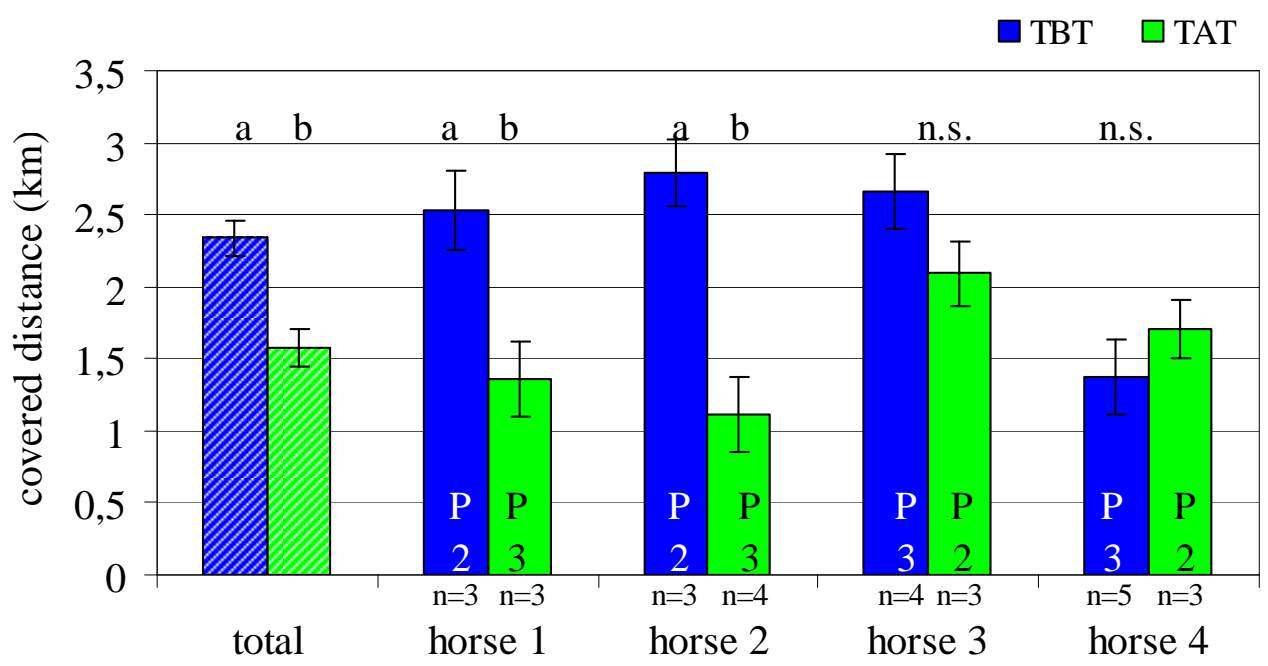

Fig. 4. Least squares means and standard error of the distance covered during turnout subdivided according to treatment. P2 and P3 mark the research period in which each horse was subjected to the respective treatment. [ $\mathrm{n}=28$; NT = not turnout; TAT = turnout after training; TBT = turnout before training; n.s. = not significant; $a, b=$ least squares means within a horse with different letters are significantly different $(P<$ $0.05)]$.

\subsection{Willingness to perform}

The horses showed "good" willingness to perform most frequently in the treatment TBT and "bad" willingness to perform most frequently in the treatment NT (Fig. 5). Hardly any variation in behaviour was documented in the treatment TAT, the horses exhibited "normal" performance most frequently. The duration of training was significantly shorter in the treatments with turnout compared to the treatment NT $(P<$ 0.02). In addition, it was seen that the more quietly the horse behaved in the working phase of training, the shorter was the duration of training $(\mathrm{r}=0.39 ; P=0.0085)$.

\section{Discussion}

\subsection{Behaviour in the stable}

The total duration of the recorded behaviours in the stable was not influenced by the treatment. The observed total duration the horses spent lying was almost exactly the same as Werhahn et al. [18] had observed in the riding horses of their group (between 2.5 and 3.0 hours). Similar results (between 2.5 and 3.5 hours lying) were found by Kiley-Worthington [3] in free-ranging and stalled horses in different housing systems. 

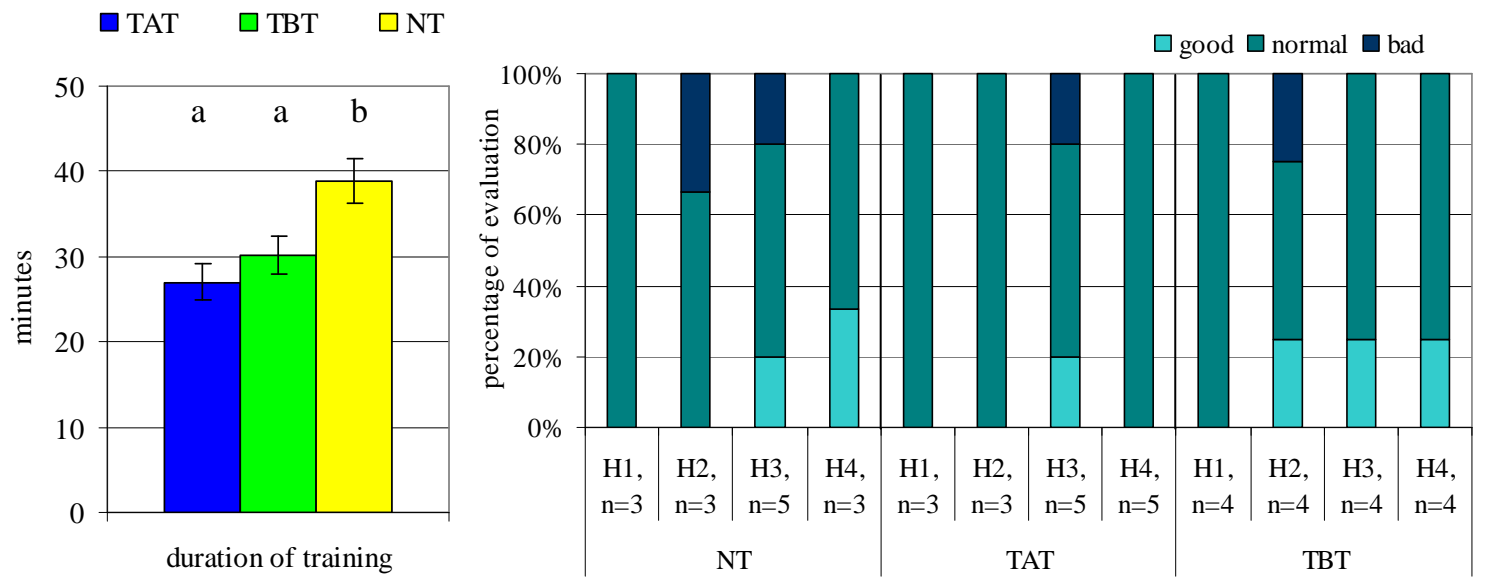

Fig. 5. Left: Least squares means and standard error of the duration of training subdivided according to treatment $[\mathrm{n}=44 ; \mathrm{a}, \mathrm{b}=$ least squares means with different letters are significantly different $(P<0.05)]$. Right: Evaluations of willingness to perform (good, normal, bad) in percent subdivided according to treatment and horse $(\mathrm{H} 1-\mathrm{H} 4) . \mathrm{NT}=$ not turnout; TAT $=$ turnout after training; $\mathrm{TBT}=$ turnout before training.

The horses in the present study showed the highest frequency of appearance of all the behaviours in the treatment NT, though the total duration was not different. That means the horses changed their behaviour more frequently in this treatment, which indicates a greater degree of nervousness and restlessness [19]. The horses appeared unsettled as well. Earlier studies also registered that the prevention of exercise leads to an accumulation of unspent energy [20], as does a long-term stay in stimulus-poor environments [21]. The decreased aggressive behaviour against their neighbours in the treatments with turnout supports the observation of a more relaxed behaviour in these horses. In the treatment TAT, the four horses showed the least frequency of all behaviours which indicates the most relaxed behaviour in this study. The relaxed behaviour in this treatment was also observed during turnout (comparatively little activity and distance covered), while the horses' willingness to perform was predominantly evaluated as "normal".

\subsection{Behaviour and distance covered during turnout}

The horses showed less activity, and so covered a smaller distance during turnout, when training was carried out before turnout (TAT). This result indicates that training does fulfil the demand for exercise at least to some extent. This was also observed by Jørgensen and Bøe [15] who found more time standing and less time walking in horses on exercise days than on no exercise days. The fact that the horses still showed active behaviour (as walking, trotting and cantering) when they were turned out after training (TAT) and so still covered a certain distance (only about 35\% less than before training), 
indicates that the demand for exercise was not fulfilled entirely by training. Chaya et al. [16] also observed significantly more active behaviour in a group of horses that was turned out once a week compared to a group of horses that was turned out six times a week, although both groups were ridden daily. They concluded that riding is not a sufficient substitute for turnout. This hypothesis can be supported by the present study. According to Hogan et al. [20], limiting natural behaviour, particularly grazing opportunities, is linked to increased activity when turnout is allowed.

Against expectations, the distances covered by Group 2 did not differ significantly between the treatments. As observed in Group 1, it was expected that the horses would show considerably less locomotion activity when they are trained before they are turned out compared to when they are turned out at first. The results in this study might have been caused by the order of the treatments. In the first period of the study, no turnout (NT) was allowed for either group, so the horses accumulated unspent energy [20] which was expressed in the second period of the study when they were turned out (Group 1 TBT; Group 2 TAT). Presumably, the horses performed a compensatory increase in locomotion as a consequence of their confinement. This reaction has been observed previously in horses [19, 21] and calves [22, 14]. The fact that training was carried out next to the turnout area might have caused some distraction. But as training was carried out to both turnout times the effect was the same for both groups.

In the present study, the horses were not able to practice social interaction in the stable. The bars between the stalls only allowed visual and olfactory contact. The results indicate that social interaction is deployed independent of the particular time of turnout, as was shown for about $16 \%$ of the turnout time both before and after training. As horses are gregarious animals, direct social interaction has great importance for their welfare. If direct contact is missing, horses easily develop stereotypic behaviour or problems in handling occur [5]. The study supported this hypothesis as the horses showed more aggressive behaviour when they did not have the possibility to practice social interactions during turnout.

\subsection{Willingness to perform}

The analyses of the riders' evaluation of the horses' willingness to perform had the best results in the treatment TBT. In this treatment, the horses showed most frequently quiet behaviour, good concentration and little contumacy. So it could not be found that turnout had any negative effects on the willingness to perform. On the contrary, in the treatment NT, the horses showed a bad willingness to perform (increased restlessness and contumacy, decreased concentration) most frequently according to the riders' answers. Rivera et al. [23] observed that young horses kept on pasture acclimatise easier to a training environment and equipment than horses housed in a stable. They traced this observation back to the fact that horses on pasture train their ability to adapt to new situations better than horses in a low-stimulus environment like a stable. The stalled horses also showed more activity like jumping and bucking, which was 
predicted by Hogan et al. [20] as being the result of unspent energy due to stabling. In the present study, the significantly longest duration of training occurred in the treatment NT. Furthermore, it was found that the duration of training was extended when the horses behaved restlessly and/or were agitated during the working phase. This was also found to occur tendencially in the study by Rivera et al. [23]. The authors explained this observation with the longer time the stabled horses needed to habituate to the equipment. This cannot be the reason in the present study, because the horses were used to training. The unspent energy due to stabling [20] seems also to be an adequate explanation for the result in the present study.

\section{Conclusions}

In conclusion, the study shows that allowing or not allowing free exercise (i.e. turnout) and the particular time of turnout effects horses' behaviour in the stable as well as in training and during turnout. The behaviour of the horses in the stable was more relaxed when turnout was allowed in addition to training. The behaviour during training was also more relaxed and the willingness to perform was not negatively affected by turnout. Furthermore, the study indicates that training does not fulfil the horses' exercise requirements. Regarding the risk of injury caused by free exercise, it is advised to allow turnout after training (TAT), because locomotion activity is decreased with this order of events compared to turnout before training (TBT). On the other hand, the horses' willingness to perform was evaluated as being better when turnout was allowed before training (TBT).

Because of the manifold individual experiences encountered by a horse until it becomes a competition horse, riders and trainers need to decide which way of management is the best for each individual animal. Generally, it has to be considered that for conventionally stalled horses, turnout in groups is the only possibility for them to perform social interactions, which is an essential element of natural behaviour and so is of great importance for animal welfare.

\section{Acknowledgements}

The authors would like to sincerely thank Ludwig Hecke and his team for enabling the experimental work to be done. 


\section{References}

[1] Korries OC. Untersuchung pferdehaltender Betriebe in Niedersachsen. Bewertung unter dem Aspekt der Tiergerechtheit bei Trennung in verschiedene Nutzungsgruppen und Beachtung haltungsbedingter Schäden [Examination of equine husbandry in Lower Saxony. Evaluation with regard to the species-specific needs of horses, differentiating between different uses and under consideration of the health damage caused by housing]. PhD Thesis, 2003, University of Veterinary Medicine Hanover, Germany.

[2] Duncan P. Time-budgets of Camargue horses. Behaviour 1980;72:26-49.

[3] Kiley-Worthington M. The behavior of horses in relation to management and training: towards ethologically sound environments. J. Equine Vet. Sci. (USA) 1990;10:62-71.

[4] Sambraus HH. Nutztierethologie. Das Verhalten landwirtschaftlicher Nutztiere Eine angewandte Verhaltenskunde für die Praxis. Hamburg: Paul Parey Verlag; 1978.

[5] BMELV. Leitlinien zur Beurteilung von Pferdehaltungen unter Tierschutzgesichtspunkten [Guidelines to evaluate housing systems for horses regarding aspects of animal welfare]. Edited by Edited by the Bundesministerium für Ernährung Landwirtschaft und Verbraucherschutz [German Ministry for Nutrition, Agriculture and Consumer Protection], 2009.

[6] Hertsch B. Belastungserscheinungen am Bewegungsapparat bei Dressur-, Springund Vielseitigkeitspferden [The appearance of stress effects in the locomotor system of dressage, show jumping and eventing horses]. Dt. tierärztl. Wochenschr. 1992;99:3639 .

[7] Bell RA, Nielsen BD, Waite K, Rosenstein D, Orth M. Daily access to pasture turnout prevents loss of mineral in the third metacarpus of Arabian weanlings. J. Anim. Sci. 2001;79:1142-1150.

[8] Arnemann S. Haltung von Sportpferden unter besonderer Berücksichtigung der Leistung [Housing of competition horses with particular consideration to performance]. PhD Thesis, 2003, University of Veterinary Medicine Hanover, Germany.

[9] Mair TS, Derksen FJ. Chronic obstructive pulmonary disease: a review. Equine Vet. Educ. 2000;12:35-44.

[10] Holcombe SJ, Jackson C, Gerber V, Jefcoat A, Berney C, Eberhardt S et al. Stabling is associated with airway inflammation in young Arabian horses. Equine Vet. J. 2001;33:244-249.

[11] McGreevy PD, French NP, Nicol CJ. The prevalence of abnormal behaviours in dressage, eventing and endurance horses in relation to stabling. Vet. Rec. 1995;137:3637.

[12] Cooper JJ, Mason GJ. The identification of abnormal behaviour and behavioural problems in stabled horses and their relationship to horse welfare: a comparative review. Equine Vet. J. 1998;27:5-9.

[13] Bachmann I, Audige L, Stauffacher M. Risk factors associated with behavioural disorders of crib-biting, weaving and box-walking in Swiss horses. Equine Vet. J. 2003;35:158-163.

[14] Dellmeier GR, Friend TH, Gbur EE. Comparison of four methods of calf confinement. II. Behavior. J Anim Sci 1985;60:1102-1109. 
[15] Jorgensen GHM, Boe KE. A note on the effect of daily exercise and paddock size on the behavior of domestic horses (Equus caballus). Appl. Anim. Behav. Sci. 2007;107:166-173.

[16] Chaya L, Cowan E, McGuire B. A note on the relationship between time spent in turnout and behaviour during turnout in horses (Equus caballus). Appl. Anim. Behav. Sci. 2006;98:155-160.

[17] Caanitz H, O’Leary L, Houpt KA, Petersson K, Hintz H. Effect of exercise on equine behavior. Appl. Anim. Behav. Sci. 1991;31:1-12.

[18] Werhahn H, Hessel EF, Bachhausen I, Van den Weghe HFA. Effects of different bedding materials on the behavior of horses housed in single stalls. J. Equine Vet. Sci. 2010;30:425-431.

[19] Mal ME, Friend TH, Lay DC, Vogelsang SG, Jenkins OC. Behavioral responses of mares to short-term confinement and social isolation. Appl. Anim. Behav. Sci. 1991;31:13-24.

[20] Hogan ES, Houpt KA, Sweeney K. The effect of enclosure size on social interactions and daily activity patterns of the captive Asiatic wild horse (Equus przewalskii). Appl. Anim. Behav. Sci. 1988;21:147-168.

[21] Houpt KA, Houpt TR, Johnson JL, Erb HN, Yeson SC. The effects of exercise deprivation on the behavior and physiology of straight stall confined pregnant mares. Anim. Welfare 2001;10:257-267.

[22] Dantzer R, Mormede T, Bluthe RM, Soissons J. The effect of different housing conditions on behavioral and adrenocortical reactions in veal calves. Reprod. Nutr. Develop. 1983;23:501-508.

[23] Rivera E, Benjamin S, Nielsen B, Shelle J, Zanella AJ. Behavioral and physiological responses of horses to initial training: the comparison between pastured versus stalled horses. Appl. Anim. Behav. Sci. 2002;78:235-252. 